・论坛・

\title{
《野生动物保护法》再修订: 背景、争点与建议
}

\author{
吕忠梅 ${ }^{*} \quad$ 陈真亮 ${ }^{2}$ \\ 1 (清华大学法学院, 北京 100084) \\ 2 (浙江农林大学文法学院, 杭州 311300)
}

摘要: 《野生动物保护法》的修订已纳入全国人大 2020 年年度立法计划。现行《野生动物保护法》虽然经过多次 修改, 但仍存在野生动物保护范围较窄、监管体制不顺、执法标准不科学、法律制度不完善等问题, 不能适应新 时代“健康中国”、“美丽中国”战略协同规制的新需求。全国人大常委会通过的《关于全面禁止非法野生动物交易、 革除滥食野生动物陃习、切实保障人民群众生命健康的决定》, 为修订《野生动物保护法》带来了良好机遇。目 前各方面对于修订《野生动物保护法》既有共识, 也有争议, 呈现出不同利益诉求与立法思维的差异性, 以及立法 过程中利益选择、利益表达、利益协调的复杂性。为此, 建议《野生动物保护法》的修订在完善立法目的、合理 界定保护范围、健全“黑白”名单制度和许可证制度、优化野生动物保护监管体制、完善激励机制和法律责任制度 等方面认真加以研究, 为促进环境治理体系和治理能力现代化 “立良法”。

关键词: 野生动物保护法; 再修订; 立法目的; 保护范围; 保护名录; 管理体制

\section{Revision of the Law of the People's Republic of China on the Protection of Wildlife: Background, issues and suggestions}

Zhongmei L $\ddot{u}^{1 *}$, Zhenliang Chen ${ }^{2}$

1 School of Law, Tsinghua University, Beijing 100084

2 School of Law, Zhejiang A \& F University, Hangzhou 311300

\begin{abstract}
An amendment to the Law of the People's Republic of China on the Protection of Wildlife has been incorporated into the annual legislative plan for 2020. Although the current Law has been revised many times, its existing problems, such as a narrow scope of wildlife protection, outdated regulatory system, uninformed law enforcement, and imperfect legal system, do not meet the new requirements and regulations put forth in the "Healthy China" and "Beautiful China" era. The decision to ban illegal wildlife trade altogether, eliminate the abuse of wild animals, and ensure people's health and safety that was adopted by the Standing Committee of the National People's Congress provides a good opportunity for revising the Law. We suggest that the revision of the Law should be carefully studied and implemented in the legislative process by reasonably defining the scope of protection, improving the "black and white" directory and licensing system, optimizing wildlife protection supervision and responsibility, and properly handling coordination with other relevant laws. These steps will promote the modernization of the environmental management system and its capacity. Key words: amendments of Law of the People's Republic of China on the Protection of Wildlife; re-revision; legislative purpose; protection scope; protected directory; management system
\end{abstract}

2020年2月24日, 全国人大常委会审议通过《关 于全面禁止非法野生动物交易、革除滥食野生动物 陃习、切实保障人民群众生命健康的决定》(以下简 称《决定》), 并宣布已将《野生动物保护法》的修 订纳入2020年年度立法计划, 意味着启动了该法的
再次修订程序。此次修法与上次修法(2016年)仅间 隔四年，可谓迅速；但透过表象，是人民群众对保 障公众健康和公共安全的新期盼成为了修法的新 动力。随着经济社会的发展和人民生活水平的不断 提高, 全社会对生态环境保护与社会文明的新需求 
日益增加, 现行《野生动物保护法》明显暴露出与 人民群众对公众健康和公共安全新期盼之间的差 距, 修订 《野生动物保护法》成为加强生态文明法 治建设的一个重要命题。但是, 实现保护生物多样 性、保障公众健康和公共安全的目标, 绝非修订法 律、更非修订一部《野生动物保护法》所能完成。 因此，在立法过程中认真听取各种不同的利益诉求， 慎重协调各种利益关系, 妥善处理各种利益保护方 式，是实现“生态善治”奠定“良法”基础的必要过程。

\section{1 修法背景: 《野生动物保护法》的实施现} 在问题

现行《野生动物保护法》于1988年颁布, 迄今 做过3次小的修正和1次大的修订。该法确立了对野 生动物“保护优先、规范利用、严格监管”的基本原 则并建立了相关保护制度和措施。我国先后加入了 《濒危野生动植物种国际贸易公约》 《生物多样性 公约》《跨界鱼类种群和高度洄游鱼类种群的养护 与管理协定》《养护大西洋金枪鱼国际公约》 《国 际捕鲸管制公约》等有关野生动物保护的国际公约 或条约以及联合国大会通过的《世界自然宪章》, 承 担大国责任并积极参与野生动物保护的国际合作。

客观地看, 经过多年努力, 我国已经初步建立 了野生动物保护的法律制度体系, 通过名录管理和 行政执法, 野生动物保护和生物多样性保护都取得 了积极进展。但是, 随着人民群众对美好生活的新 期待和 “美丽中国”建设步伐的加快, 野生动物保护 法律制度的一些不足也逐渐暴露。近年来, 人畜共 患疾病多发乃至致人死亡的事件在世界范围内屡 屡发生。我国环境与健康风险管理工作面临巨大压 力, 环境与健康风险管理基础数据缺乏、技术支撑 不足等问题依然突出; 环境与健康风险管理制度建 设、公民环境与健康素养水平与经济社会发展的协 调性亟待增强。尤其是近年来发生的一些突发公共 卫生事件，凸显一个法律“短板”: 已经基本形成的 中国特色社会主义法律体系中, 有效保障公众环境 与健康权益的法律供给严重不足。其外在表现是: 野生动物保护法律制度缺乏对于公众健康保障的 目的性考量，多头立法、单项立法导致不同法律间 的矛盾与冲突, 法律的系统性、协调性、空间性不 足，未能实现对“健康中国”和“美丽中国”战略的协 同规制。

\section{1 “只保护重点野生动物”的取向难以实现保护 生物多样性的立法目标}

现行《野生动物保护法》规定了“保护野生动 物, 拯救珍贵、濒危野生动物, 维护生物多样性和 生态平衡，推进生态文明建设”的立法目标，明确 了本法规定保护的野生动物“是指珍贵、濒危的陆 生、水生野生动物和有重要生态、科学、社会价值 的陆生野生动物”。这将法律保护的野生动物限定 在较小范围内，体现的是以鼓励开发利用野生动物 为主的立法取向; 同时, 该法第38条规定可以自 由、自主地放生野生动物，未提出风险评估和审核 许可要求。这也在一定程度上弱化了该法所确立的 生物多样性保护目标, 对可能造成的生物入侵、公 共安全及公众健康风险等潜在威胁缺乏严格规制 与风险预防措施。

为实施《野生动物保护法》, 《陆生野生动物 保护实施条例》《水生野生动物保护实施条例》《濒 危野生动植物进出口管理条例》《国家重点保护野 生动物驯养繁殖许可证管理办法》等行政法规规章 先后发布。根据威科法律数据库(https://law.wkinfo. com.cn，检索时间2020年2月1日)的检索结果，全国 约有 20 个省(自治区、直辖市)颁布了实施性地方法 规、规章并进行过相应的修订或修正。浙江、云南、 河北等还颁布了省级陆生野生动物保护条例。这些 国家和地方立法基本上按照保护 “珍贵、濒危的陆 生、水生野生动物和有重要生态、科学、社会价值 的陆生野生动物”的思路, 将有重要生态、科学、社 会价值的“水生”野生动物，以及非“重点”保护的一 般动物(比如实验动物、畜离、宠物、娱乐动物、流 浪动物等)排除在外。

从立法实践看，对一般动物的保护并非完全没 有法律涉及, 只是分散在《畜牧法》《动物防疫法》 《渔业法》《食品安全法》《进出境动植物检疫法》 等法律，以及《实验动物管理条例》《兽药管理条 例》 《动物源性饲料产品安全生产管理办法》等法 规规章中。这些法律法规规章虽涉及动物及其保护, 但立法宗旨各异、立法形式和效力层级不同。比如 《畜牧法》是“为了规范畜牧业生产经营行为, 保障 畜禽产品质量安全，保护和合理利用畜禽遗传资源， 维护畜牧业生产经营者的合法权益，促进畜牧业持 续健康发展”; 《动物防疫法》是 “为了加强对动物 防疫活动的管理, 预防、控制和扑灭动物疫病, 促 
进养殖业发展, 保护人体健康, 维护公共卫生安 全”; 《实验动物管理条例》是“为了加强实验动物 的管理工作, 保证实验动物质量, 适应科学研究、 经济建设和社会发展的需要”。这些立法基本上未 将野生动物保护纳入立法目的, 更缺乏对生物安全 和生物多样性保护的统筹考虑。

\section{2 “集管理与监督于一体”的监管体制难以贯彻 “保护优先、规范利用”的基本原则}

《野生动物保护法》第7条规定: “国务院林业草 原、渔业主管部门分别主管全国陆生、水生野生动 物保护工作。县级以上地方人民政府林业草原、渔 业主管部门分别主管本行政区域内陆生、水生野生 动物保护工作。”据此，国务院林业草原、渔业主管部 门既有权制定重点保护野生动物名录, 也有权发放野 生动物资源利用许可证, 还有权对野生动物保护情况 进行监督执法。这导致主管部门的监督与管理职能合 一, 一个部门“既作运动员、又作裁判员”, 影响法律 的有效实施，不利于“保护优先”原则的贯彻落实。

实际上, 野生动物资源的开发利用和保护涉及 多种行为, 有监管职责的除林业草原、农业农村主 管部门外, 至少还与生态环境、市场监管、卫生健 康、公安等部门的职责有关, 但各部门执法的法律 依据并不相同。由于多部法律法规之间缺乏协调, 导致各部门的监管范围和职责存在一定交叉、重叠 甚至冲突。同时, 由于缺乏系统科学的溯源体系和 监督检查方式，导致现实中难以区分野生动物个体 或制品的合法/非法来源，出现许可证发放后的监 管乏力、执法不严、执法怠惰等问题。比如, “捕猎 一运输一贩卖一消费” 野生动物的黑色利益链时隐 时现, 有的“野味”市场和网络交易平台商家利用驯 养繁殖许可证、经营利用许可证、狩猎证、生产专 用标识, 专门从事名为养殖、狩猎实为贩卖的“洗 白”交易。再如, 野生动物被捕获后申报动物检疫的 极少, 持动物防疫合格证销售野生动物的极少, 市 场监管缺位现象十分严重。这也使得“规范利用”原 则难以落实。

\section{3 “分部门制定名录”模式不能提供“严格监管” 的科学标准}

《野生的动物保护法》第10条规定: “国家对野 生动物实行分类分级保护。国家对珍贵、濒危的野 生动物实行重点保护。国家重点保护的野生动物分 为一级保护野生动物和二级保护野生动物。国家重
点保护野生动物名录, 由国务院野生动物保护主管 部门组织科学评估后制定, 并每五年根据评估情况 确定对名录进行调整。国家重点保护野生动物名录 报国务院批准公布。……有重要生态、科学、社会 价值的陆生野生动物名录, 由国务院野生动物保护 主管部门组织科学评估后制定、调整并公布”。根 据该法授权，相关名录由林业草原部门、农业渔业 部门分别制定。

到目前为止，国家先后发布了 8 个相关名录， 包括: (1) 1989年经国务院批准，原林业部和农业部 发布的《国家重点保护野生动物名录》(2003年2月 21日，原国家林业局对该名录进行了调整，将㭩科 鹿属(Moschus spp.)所有种由国家二级保护野生动 物调整为国家一级保护野生动物); (2) 2000年原国 家林业局发布的《国家保护的有益的或者有重要经 济、科学研究价值的陆生野生动物名录》; (3) 2006 年原农业部发布的《国家级畜禽遗传资源保护名 录》(2014年，农业部对该名录进行了修订); (4) 2007 年原农业部发布的《国家重点保护经济水生动植物 资源名录》; (5) 2017年原国家林业局发布的《人工 繁育国家重点保护陆生野生动物名录(第一批)》; (6) 2018年农业农村部发布的《〈濒危野生动植物物种 国际贸易公约〉附录水生动物物种核准为国家重点 保护野生动物名录》; (7) 2017年原农业部发布的 《人工繁育国家重点保护水生野生动物名录(第一 批)》; (8) 2019年农业农村部发布的《人工繁育国家 重点保护水生野生动物名录(第二批)》。

分析这些名录可以发现一些明显问题：一是 《国家重点保护野生动物名录》的保护种类范围过 窄、数量过少，且没有及时进行更新和拓展; 二是 《人工繁育国家重点保护野生动物名录》的种类数 量扩张较快, 并且已将许可权限下放到县级部门; 三是对于家畜家禽和人工饲养、合法捕获的“其他 动物”没有分类分级保护名录; 四是名录分级分类 的标准由不同部门确定，导致一些“两栖”动物归属 不明。此外, 国家级和地方级重点保护野生动物栖 息地名录与国家级、地方级自然保护区、国家公园 存在一定的交叉和重叠。这些问题的存在，使得名 录制度不能起到为严格监管提供科学依据的作用。

现行《野生动物保护法》存在的问题, 有的曾 在过去的修法方案中被提出但修订难度很大，比如 扩大野生动物保护范围、加大对养殖野生动物行为 
的限制等, 都在2016年的修法草案中提出过, 却因 各种原因未能完成修订(中华人民共和国全国人民 代表大会常务委员会, 2016)。在国务院机构改革之 后, 中共中央、国务院《关于构建现代环境治理体 系的指导意见》发布之际， 《野生动物保护法》的 再次修订迎来了最佳窗口期。经调研, 各方面对解 决野生动物保护的立法目标、体制机制、执法标准 等问题呼声强烈、期望很高。

\section{2 主要争点: 《决定》对《野生动物保护法 的影响及对相关问题的不同解决方案}

2020年2月24日, 全国人大常委会审议通过的 《决定》, 是全国人大常委会履行宪法和法律规定 的制定法令、解释法律、修改法律、补充法律、批 准条约等职权的立法活动, 具有解释法律和补充法 律的双重作用。笔者认为, 《决定》对《野生动物保 护法》的修订在立法目的、“野生动物”的法律概念 及保护范围、监管体制、监管方式、法律责任等方 面都有直接的指导作用(曹俊，2020)。近一段时间， 理论界与实务界围绕贯彻实施《决定》和对《野生 动物保护法》的修订进行了热烈讨论, 各种利益诉 求表达非常充分。这些讨论所聚焦的问题和达成的 基本共识能够为修法工作奠定良好的民意基础，立 法机关可以分析后加以吸纳。为此, 本文选取了两 份相对完整并具有学科代表性的《野生动物保护 法》修订建议作为分析样本, 一份是中国法学会行 政法学研究会提出的修法建议(以下简称“行政法学 者建议稿”)(http://iolaw.cssn.cn/jyxc/202002/t20200214_ 5088725.shtml, 获取时间2020年3月20日), 另一份 是北京大学自然保护与社会发展研究中心等九家 单位联合提出的修法建议(以下简称“联合建议稿”) (http://www.fon.org.cn/index.php?option=com_k2\&view= item\&id=14012:2020-02-20-14-05-51, 获取时间 2020 年3月20日), 以观察法学界和环境保护界对同一问 题的不同观点。同时, 兼顾一些重要的学术观点和 相关部门的执法实践, 归纳出修订《野生动物保护 法》的五个重点问题, 以展示立法活动中不同利益 诉求与不同利益表达方式须经过法定程序加以协 调才能最终形成国家意志的过程。

\section{1 《野生动物保护法》的立法目的是否应该以及 如何修订?}

《决定》明确了“维护生物安全和生态安全, 有
效防范重大公共卫生风险，切实保障人民群众生命 健康安全, 加强生态文明建设, 促进人与自然和谐 共生”的目标要求。两个建议稿均认为应该对《野 生动物保护法》的立法目的进行修订，但对如何修 订有不同方案。

“行政法学者建议稿”的方案是: 确立野生动物 普遍保护的理念，同时引入公共卫生和健康的视角， 在立法目的中增加有关尊重生命、倡导文明和维护 人群健康和生物安全方面的内容; 在立法原则上, 增加生命伦理和生物安全的内容。

“联合建议稿”的方案是：在确立野生动物普遍 保护理念的同时, 引入公共卫生和健康的视角, 强 调从公共卫生的维度开展野生动物保护, 建议将 “保障生态安全与公共卫生安全”纳入立法目的。

也有个别学者认为: 野生动物保护法立法目的 调整需要慎重考虑, “保障公众健康和公共卫生安 全”、“尊重生命伦理”等内容不宜加入到立法目的中, 这些内容不属于《野生动物保护法》的调整范围。 为此, 有学者建议分别立法, 在执法过程中再根据 不同场景适用适当的法律(蒲晓否, 2020)。

\section{2 《野生动物保护法》中的“野生动物”应该如何} 界定?

《决定》扩大了“野生动物”的禁食范围, 意味着受 法律保护的野生动物范围已不再是现行《野生动物保 护法》规定的“重点保护动物”和“有重要生态、科学、 社会价值的” “三有”动物, 修法时必须重新定义受法 律保护的“野生动物”概念。两个建议稿对重新界定 “野生动物”没有分歧，但对定义方式有不同意见。

“行政法学者稿”建议借鉴有关国际公约和国 际惯例, 重新对野生动物进行界定。除却一些经 科学论证明显对人类有害可不用保护的野生动物, 其他的一切野生动物都应纳入立法保护的范围, 并依据野生动物的生态功能与种群现状等实行分 类保护。

“联合建议稿”则提出要明确“野生动物”的定义, 扩大《野生动物保护法》适用范围至所有野生动物; 厘清《野生动物保护法》和其他法律之间的关系, 将 一部分野生动物纳入其他相关法律的规定范围; 不 再保留“有重要生态、科学、社会价值”的“三有”概 念。建议借鉴有关国际公约和国际惯例, 将“野生动 物”定义为“生活在自然状态下和人工环境里未经人 类驯化的动物”。 


\section{3 《野生动物保护法》是否应该确立“黑、白”名} 单以及如何确立?

《决定》明确将列入畜禽遗传资源目录的动物 排除在禁食范围之外, 规定因科研、药用、展示等 特殊情况可以对野生动物按照国家有关规定进行 非食用性利用, 并要求对《国家级畜禽遗传资源保 护名录》及时进行调整。对《决定》规定的“黑、 白”名单制度是否应“平移”至《野生动物保护法》, 甚至是否应该制定“白名单”，各方面有不同认识， 比如北京林业大学野生动物研究所时坤教授认为 禁止食用野生动物不存在“黑白名单”(https://guancha. gmw.cn/2020-03/06/content_33625525.htm)。两个建 议稿对“黑、白名单”的具体内容也有不同方案。

“行政法学者稿”主张建立“黑名单”制度, 建议 将可食用的野生动物限定在极小范围内, 采用清单 式管理，清单外的一律禁止食用。借鉴国际公约的 名录做法，公布不可食用的野生动物及其制品名录， 将地方保护的非珍贵、濒危野生动物, 传统的“三 有”动物, 以及那些可能更容易引发公共卫生问题 的动物(如刺猬、蝙蝠、穿山甲、蜈蚣、毒蛇等)可 以考虑采取特殊保护措施, 允许科研利用和灭杀, 但严禁食用。将可食用野味等同于肉类食品予以严 格监管，实行严格的检验检疫制度。

“联合建议稿”则提出了建立“黑、白”名单制度, 具体建议为: 根据名录和许可, 对野生动物利用进 行分类管理; 依照科学原则, 及时制定和更新名 录。将野生动物分为国家和地方重点保护野生动物 和一般保护野生动物, 对于列入国家重点野生动物 保护名录和地方重点保护野生动物保护名录的野 生动物实行严格保护; 除因科学研究、种群调控、 迁地保护、疫源疫病监测或者其他特殊情况向野生 动物保护行政主管部门申请许可后方可猎捕外, 禁 止猎捕、杀害野生动物, 野外捕猎的野生动物不得 用于商业目的或进入市场进行交易和利用; 对人工 繁育陆生野生动物, 明确划分商业与非商业目的, 区别管理; 为满足一定条件的动物建立保护性的 “特种繁育动物名录”。

也有学者认为: 《决定》中规定的列入畜禽遗传 资源目录的动物属于家畜家禽, 应适用《畜牧法》 的规定, 实行以禽畜遗传资源目录为标准的正面清 单管理, 扩大家畜家禽的范围, 对目录的设置提出 了非常高的要求。事实上, 家畜家禽的范围即使再
扩大也不能囊括所有可安全利用的野生动物, 比如 不属于家畜家禽的两栖类和爬行类动物; 也不能囊 括事实上被长期安全利用的国家重点保护动物, 如 梅花鹿。对此, 《野生动物保护法》应当明确要求, 尽快出台配套细则, 将禽畜遗传资源目录扩充为安 全驯养动物目录(蒲晓磊, 2020)。

2020年5月1日起生效实施的《深圳经济特区全 面禁止食用野生动物条例》将可以食用的动物规定 为“国家畜禽遗传资源目录所列的猪、牛、羊、驴、 兔、鸡、鸭、我、鸽、鹤鹑以及该目录所列其他以 提供食用为目的饲养的家禽家畜，以及依照法律、 法规未禁止食用的水生动物”。该地方立法建立了 “白名单”制度，进一步扩大了全国人大《决定》的 禁食范围。

\section{4 《野生动物保护法》的监管体制应该如何建立?}

《决定》要求各级人民政府及其有关部门健全 执法管理体制, 为《野生动物保护法》的修订与完 善监管体制机制提供了依据。目前，各方面对于应 进一步完善野生动物保护执法管理体制已有共识, 但对于如何建立健全监管体制则有不同方案。两份 建议稿均提出成立专门的野生动物保护局作为执 法部门，对于是否建立以及如何建立协调机制、监 督机制有不同认识。

“行政法学者稿”建议将陆生野生动物保护职能 划归自然资源部, 在自然资源部成立野生动物保护 局，一方面提高其法律地位，增加其行政资源; 另 一方面可以利用自然资源部门的管理和执法力量, 有效提高管理和执法水平。

“联合建议稿”提出，整合林草部门和农业渔业 部门的野生动物保护职责后划归自然资源部, 在自 然资源部成立野生动物保护局; 明确生态环境部负 有监督全国陆生、水生野生动物保护执法情况，对 林业草原、农业农村主管部门的野生动物保护执法 工作提出监督和加强执法意见的具体职责。同时, 设立独立和公开的科学委员会, 指导并监督相关配 额制定、名录设定和更新调整等专业性问题。

在实践层面，地方林草、农业、生态环境等部 门也提出了《野生动物保护法》与《环境保护法》 所建立的生态环境监管体制是否需要衔接以及如 何衔接的问题。

\section{5 《野生动物保护法》的法律责任制度应如何完善?}

《决定》明确规定, 加大对野生动物非法交易行 
为的惩罚力度, 明确加重处罚和新增处罚的内容, 体现出提高违法成本、完善法律责任制度的明确导 向。对此, 各方面的意见高度一致, 但提出的完善 法律责任制度的侧重点有所不同。

“行政法学者稿”的建议相对系统, 从提高行政 处罚标准、修改刑法两个方面提出了强化法律责任 的建议。具体为提高行政罚款额度, 将现行《刑法》 第341条修改为“非法猎捕、杀害、运输、贩卖、购 买和食用野生动物罪” 和 “非法收购、运输、出售野 生动物制品罪”，同时增加“虐待野生动物罪”。

“联合建议稿”认为应补充规定禁止生产、经营、 运输、携带、寄递野生动物及其制品制作的食品(包 括特种繁育动物及其制品制作的食品)及法律责任; 同时，规定非法消费野生动物行为的法律责任。

本质上看，立法决策实际上是对各种利益诉求 按照一定价值取向或者标准的取舍, 不同利益诉求 的充分表达和博弯是形成国家意志的必经之路。不 同的建议方案实际上代表着不同的利益诉求。立法 决策者对于各种不同的利益诉求不应简单地采纳 或排斥, 而是要经由立法程序, 在立法机关内部形 成初步方案后, 面向社会全体成员征求意见。在各 方面反复的利益表达、利益协商、利益妥协过程中, 逐步达成多数人的意见, 最终形成具有法律效力的 法律。立法过程的民主化, 是法律能够得到社会更 好认同和遵守的前提。理性分析各种不同意见，事 关立法决策的科学化。

\section{3 具体建议: 对《野生动物保护法》修订重点 的基本思路}

《决定》发布后, 国家林草局、农业农村部、生 态环境部出台了实施方案, 并在实践中加大了执行 力度。这些实践对《野生动物保护法》的修订具有 很好的经验积累作用。按照全国人大常委会的立法 计划, 2020年将制定《生物安全法》, 启动《野生动 物保护法》及相关法律法规的修订工作, 目的在于 通过立法建立“安全阀”，控制环境与健康“风险源”, 完善我国的生物安全和公共卫生立法体系。这也为 更好修订《野生动物保护法》提供了难得的系统性 立法契机。

野生动物保护事关人类可持续发展全局, 是建 立和维护“全球生命共同体”的重要内容。从世界范 围看, 人类在野生动物保护方面面临着四个难题:
一是宏观上解决人类与野生动物、野生动物与动 物、野生动物保护与生态系统保护之间的关系问 题。二是微观上解决来自各个方面的对野生动物及 其栖息地的威胁问题。三是应对野生动物给人类社 会和生态系统带来的威胁的具体措施。四是根据各 国国情，综合考虑野生动物资源分布、立法体制、 立法技术、文化传统和管理水平等各方面因素，合 理选择野生动物保护立法模式问题。因此, 笔者认 为《野生动物保护法》的修订还应该有更高的站位 和更开阔的视野，理性审视存在的问题，综合考虑 立法价值取向与立法技术的有机结合，妥善处理 《野生动物保护法》与相关法律的关系, 为促进国 家治理体系和治理能力现代化“立良法”(曹俊, 2020)。根据当前对《野生动物保护法》修订重点问 题的归纳, 结合我们前期所进行的调查研究工作, 对贯彻落实《决定》精神, 提出如下修订《野生动 物保护法》的思路性建议。

\section{1 增加 “保障公众健康和公共卫生安全”的立法 目的}

现行《野生动物保护法》将立法目的确定为保 护生物多样性是正确的，但其“就野生动物保护谈 野生动物保护”的立法思维缺乏对野生动物保护所 可能涉及的生态安全、公共卫生安全风险的关联性 考虑。尤其是对 “野生动物”的法律内涵界定较窄, 没有把与公众健康和公共卫生安全有关的动物纳 入保护范围，导致一些“野生的动物”没有纳入法律 调整范围，不能从法律上对相关交易、食用行为加 以遏制。因此, 有必要将保障公众健康、维护公共 卫生安全的理念在《野生动物保护法》中加以体现, 并以此为基础进行相关制度的衔接性安排, 通过重 新定义“野生动物” 以弥补现行法律的不足。按照新 的价值目标对《陆生野生动物保护条例》 《水生野 生动物保护实施条例》《国家重点保护野生动物驯 养繁殖许可证管理办法》等相关法规规章进行评估, 统筹考虑我国动物保护立法体系的建构, 决定是否 有必要在《野生动物保护法》以外，对一般动物、 实验动物、伴侣动物等进行分层次专门立法，进一 步促进我国动物保护立法的综合化和体系化。

同时, 将《野生动物保护法》适用范围扩大至 所有野生动物, 除了非国家重点保护的水生野生动 物适用《渔业法》等法律以外，对农业、林业、公 共卫生有影响的陆生野生无脊椎动物, 以及可作为 
特种繁育陆生野生动物进行商业利用的人工繁育 种群, 适用《农业法》《森林法》《传染病防治法》 《畜牧法》《动物防疫法》等法律进行管理。

\section{2 重新界定“野生动物”概念}

根据《决定》精神, 将《野生动物保护法》的 适用范围扩大到没有被人类驯化且生活在自然界 中的所有动物。我们从已经收集到的 9 个国家、 2 个 地区与野生动物保护相关的规范文件以及 3 个国际 组织或公约对 “野生动物”的法律定义来看, 这些法 律定义存在着科学性、细致程度上的差异。其中, 加 拿大《野生动物法》《濒危物种法》, 美国《鱼类 和野生动物协调法》《雷斯法案》, 澳大利亚《国 家公园和野生动物法》《环境与生物多样性保护法》 对野生动物的相关定义具有借鉴价值。应尊重野生 动物保护的科学规律, 考虑人工控制管理干预的强 度和人工选择时间长短的连续变化因素, 对 “野生 动物”的概念进行合理定义(曾岩等, 2020)。

我国可采取概括和列举相结合的立法技术方 法, 对野生动物、国家重点保护野生动物、CITES 公约附录I和附录II中的野生动物、难以人工繁育的 野生动物(如虎、狮、熊等)等术语进行界定。同时 对 《畜牧法》 《动物防疫法》 《森林法》 《农业法》

《渔业法》 《食品安全法》等法律中的“动物”或“野 生动物”的概念采取“打包修法”方式进行统一修改, 以保证法律定义的内在统一、法律制度的协同配合。

\section{3 完善名录制度和许可证制度}

野生动物保护涉及生物学、生态学、环境科学 等多个自然科学领域, 《野生动物保护法》的核心 制度是“名录”和“许可”。“名录”的提出、确定和调 整在很大程度上有赖于科学研究成果, “许可”必须 建立在科学的 “名录”基础之上。现行野生动物保护 法实施中出现的很多问题都与 “名录”、许可证的不 科学管理直接相关。要将《野生动物保护法》修订 得既“管用”又 “好用”，必须采取法律和科技相结合 的方式，由科学家与法学家紧密合作，共同完成野 生动物保护立法中的科学技术规范法律化和法律 技术规范化工作。

《野生动物保护法》中的“名录制度”应包括与 制定 “名录”有关的调查、评估、调整等相关主体与 程序规定。在国家层面应建立由生态环境保护、经 济管理、社会治理、法律等相关领域专家组成的专 家委员会, 负责提出统一的野生动物保护名录并及
时评估调整; 制定保护动物的利用规模、程度、方 法等科学标准，作为发放许可证的科学依据，从而 解决多部门执法、名录不统一、标准不统一问题，减 少法律实施中的矛盾与冲突。修法过程中，也应组 织专家对现有的各类名录进行生态、经济、社会、 法律等方面的评估，提出系统性修改意见。对重点 保护野生动物名录、重点保护野生动物栖息地名录, 根据生物多样性保护、珍稀濒危物种保护、野生动 物栖息地保护、遗传资源保护等不同目的，提出差 异化保护建议并提交立法机关审定。对于“黑、白” 名单，可以根据保护程度和规模的不同需要，授权 国务院相关部门和地方分别发布。

许可证管理是国内外实践已证明对于保护野 生动物十分有效的法律制度，应在现有规定的基础 上加以完善。充分发挥许可证管理的优势，针对每 个监管对象采取具体措施，设定具体许可条件和限 制, 将开发利用野生动物的规模和程度控制在合理 的范围之内，以确保生物多样性保护、生物安全和 公众健康立法目标的实现。建立野生动物放生许可 制度，许可证发放须以科学论证和风险评估为前置 条件，避免造成生物入侵和生态损害。可参考排污 许可证综合改革的经验，吸纳其中的合理因素，完 善《野生动物保护法》的许可证管理制度。

\section{4 优化野生动物保护执法及多元治理体系}

野生动物的保护和监管是一项系统工程，涉 及中央的林业草原、农业、生态环境、公安、交 通运输、动物防疫、卫生健康、市场监管等多个 部门和各级地方人民政府及其职能部门的职责权 限。现行《野生动物保护法》共出现了 42 次“野生 动物保护主管部门”，但没有对其职责予以具体 明确，没有规定县级以上地方人民政府的组织协 调职责, 导致出现执法中的乱象。因此, 修订《野 生动物保护法》必须重点解决执法与监管体制问 题，明确相关部门的职责权限及其协调原则和机 制。应以决策、规划、开发利用、执法、监督权 限分设并相互制约为原则，解决不同部门之间的 职责分工与协调、合作与协同问题。考虑《野生 动物保护法》与《环境保护法》的衔接, 建立野 生动物保护的统一监管与专业执法分立机制。

在新设立野生动物保护局有相当困难的现实 情况下，可考虑从增加管理职能，建立协同、联合 执法机制等方面来解决。在明确规定野生动物保 
护主管部门为国务院和县级以上地方人民政府的 林业草原、渔业主管部门的基础上, 由林草部门 牵头建立联合执法协调机制, 将有相关职能的部 门均纳入进来。同时, 增加规定县级以上地方人 民政府加强野生动物保护和监督管理工作的组织 领导和协调职能。

建议将野生动物保护法律法规的执行情况纳 入中央环保督察范围, 将野生动物保护工作纳入地 方党委、政府的生态文明建设绩效考核指标体系, 压实地方政府在野生动物保护和管理方面的属地 责任, 明确野生动物交易监管过程中监管权责的合 理分配与归属问题。将野生动物保护工作纳入社会 治理体系，综合利用命令控制、市场激励和公众参 与等治理手段, 提高野生动物保护的制度效能。按 照国家环境治理体系与治理能力现代化的总体要 求, 鼓励公众参与和社会自治, 保障各利益相关方 的知情权、表达权、参与权、监督权与诉讼权。

\section{5 完善激励和约束性法律制度}

野生动物的保护和管理涉及面广、环节多, 需要相关部门和全社会之间加强沟通、互相配合、 协调推进。《野生动物保护法》应建立适当的经 济激励和奖励制度, 鼓励地方政府、企业主动采 取野生动物保护措施; 奖励为野生动物保护做出 突出贡献的单位、社会组织和个人; 将企业和个 人的相关行为纳入社会诚信体系范围。

明晰的法律责任制度对 《野生动物保护法》 的实施至关重要。应根据新建立的体制机制和主 要制度设计相应的法律责任, 明确违法利用野生 动物的法律责任。在建立权责利相统一的政府权 力清单、负面清单、“白名单”和“黑名单”、许可 证等制度的基础上，完善政府相关主管部门负责
人及其工作人员的行政责任; 强化企事业单位和 个人的行政法律责任、民事法律责任和刑事法律 责任。建议建立野生动物保护公益诉讼制度、生 态环境损害赔偿制度，发挥司法机关监督作用， 加强野生动物保护司法; 完善野生动物保护社会 动员机制，形成野生动物保护的治理合力。

\section{参考文献}

The Standing Committee of the National People's Congress of the People's Republic of China (2016) The Law of the People's Republic of China on the Protection of Wildlife (Revision). China Legal Publishing House, Beijing. (in Chinese) [中华人民共和国全国人民代表大会常务委员会 (2016)中华人民共和国野生动物保护法(2016年修订版). 中国法制出版社，北京.]

Cao J (2020) What are the key points of wildlife protection? -Dialogue with Lü Zhongmei, member of the Standing Committee of the 13th CPPCC National Committee, vice president of the China Law Society and head of the China law society environmental and Resource Law Research Society. China Ecological Civilization, (1), 31-38. (in Chinese) [曹俊(2020)野生动物保护：修法要点是什么?

对话十三届全国政协常委、中国法学会副会长、中 国法学会环境资源法学研究会负责人吕忠梅. 中国生态 文明, (1), 31-38.]

Pu XL (2020) Three important points for revising the wildlife protection law. Legal Daily, 2020-03-17. (in Chinese) [蒲晓 磊(2020)野生动物保护法修改三大看点. 法制日报, 2020-03-17.]

Zeng Y, Ping XG, Wei FW (2020) A conceptual framework and definitions for the term "wild animal". Biodiversity Science, 28, 541-549. (in Chinese with English abstract) [曾 岩，平晓鸽，魏辅文(2020)“野生动物”的概念框架和术语 定义. 生物多样性, 28, 541-549.]

(责任编委：马克平 责任编辑: 周玉荣) 